\title{
Personality Traits of Hospital Pharmacists: Toward a Better Understanding of Factors Influencing Pharmacy Practice Change
}

\author{
Jill Hall, Meagen Rosenthal, Hannah Family, Jane Sutton, Kevin Hall, and Ross T Tsuyuki
}

\begin{abstract}
Background: The profession of pharmacy has adopted a mandate to become more patient-centred; however, significant change in this direction has not been achieved.

Objective: To characterize the personality traits of hospital pharmacists in one Canadian province, to provide insights into potential barriers to practice change.

Methods: A cross-sectional survey of hospital pharmacists was conducted in Alberta, Canada. An invitation to participate was sent to all 766 hospital pharmacists practising in the province's 2 health service organizations. The survey was based on the Big Five Inventory, a validated, reliable instrument that uses a 5-point Likert scale to measure the traits of extraversion, agreeableness, conscientiousness, neuroticism, and openness.
\end{abstract}

Results: Of the 347 pharmacists who completed the survey (45\% response rate), the majority (297 [86\%]) were staff pharmacists working full time in an urban setting. The average age of respondents was 41 years (standard deviation [SD] 11 years), and the average period in practice was 17 years (SD 11 years). Respondents' mean scores were 3.2 (SD 0.7) on extraversion, 3.8 (SD 0.4) on agreeableness, 4.0 (SD 0.4) on conscientiousness, 2.5 (SD 0.7) on neuroticism, and 3.5 (SD 0.6) on openness. Total frequency counts revealed that respondents tended toward stronger expression of extraversion, agreeableness, conscientiousness, and openness and low levels of neuroticism (with the latter indicating stability).

Conclusion: The Big Five Inventory represents a novel approach to examining pharmacists' change-related behaviours. Improving understanding of hospital pharmacists' personality traits will provide insights for the development of training and support programs tailored specifically to this group.

Keywords: pharmacy practice change, personality traits, Big Five Inventory, hospital pharmacy practice

Can J Hosp Pharm. 2013;66(5):289-95

\section{RÉSUMÉ}

Contexte : La profession de la pharmacie s'est donné pour mandat d'être plus axée sur le patient, mais les changements importants pour y parvenir n’ont pas été au rendez-vous.

Objectif : Caractériser les traits de la personnalité des pharmaciens d'hôpitaux d'une province canadienne afin de dégager une meilleure compréhension des obstacles potentiels aux changements dans la pratique.

Méthodes : Une enquête transversale a été menée en Alberta, au Canada, auprès de pharmaciens d'hôpitaux. Une invitation à y participer a été envoyée aux 766 pharmaciens d'hôpitaux exerçant dans les deux organismes de services de santé de la province. L'enquête était basée sur l'Inventaire des cinq grands facteurs de personnalité (Big Five Inventory), un instrument validé et fiable utilisant une échelle de Likert à 5 points pour mesurer l'extraversion, l'agréabilité, la conscience, le névrosisme et l'ouverture.

Résultats : Des 347 pharmaciens ayant participé à l'enquête (taux de réponse de $45 \%)$, la majorité (297 [86 \%]) était des pharmaciens pratiquant à temps plein en milieu urbain. Lâge moyen des répondants était de 41 ans (écart-type [ÉT], 11 ans) et la période d'exercice moyenne était de 17 ans (ÉT, 11 ans). Les scores moyens des répondants étaient les suivants : extraversion : 3,2 (ÉT, 0,7); agréabilité : 3,8 (ÉT, 0,4); conscience : 4,0 (ÉT, 0,4); névrosisme : 2,5 (ÉT, 0,7); et ouverture : 3,5 (ÉT, 0,6). Le nombre total d'occurrences a révélé une tendance des répondants à une plus forte expression des facteurs d'extraversion, d'agréabilité, de conscience et d'ouverture, et à un faible taux de névrosisme (ce dernier facteur exprimant la stabilité émotionnelle).

Conclusion : L'Inventaire des cinq grands facteurs de personnalité représente une approche novatrice pour évaluer les comportements des pharmaciens face au changement. Une meilleure compréhension des traits de personnalité des pharmaciens d'hôpitaux permettra de dégager les données nécessaires au développement de programmes de formation et de perfectionnement propres à ce groupe.

Mots clés : changement de la pratique de la pharmacie, traits de personnalité, Inventaire des cinq grands facteurs de personnalité, pratique de la pharmacie hospitalière

[Traduction par l'éditeur] 


\section{INTRODUCTION}

$\mathrm{T}$ he Blueprint for Pharmacy has articulated a vision for the profession of pharmacy in Canada that focuses on patientcentred care. ${ }^{1}$ Recently, health system pharmacy organizations in both Canada and the United States have developed vision statements to guide the improvement of patient outcomes and safety by advancing practice excellence. ${ }^{1-3}$ However, advancement toward this objective has been slow and incomplete. ${ }^{4-9}$ For example, a survey conducted in 2007 found that the majority of pharmacist respondents spent their work time on dispensingrelated activities, although they were interested in and recognized the need for practice change. ${ }^{7}$ British Columbia pharmacists have had the authority to adapt prescriptions since $2009^{8}$; however, adapted prescriptions accounted for only $0.2 \%$ of all prescription claims in that year.' In Alberta, pharmacists have been allowed to apply for additional prescribing authorization since $2007,{ }^{10}$ but only 215 of the roughly 4000 pharmacists in the province have received this authority (D Cooney, Deputy Registrar, Alberta College of Pharmacists; personal communication by e-mail, January 24, 2013).

Recent work in the area of practice change in pharmacy is beginning to suggest that pharmacists themselves may be the most important barrier to the adoption of more advanced forms of practice. ${ }^{11,12}$ In previous work exploring the professional culture of pharmacy, we posed the question "What does a pharmacist do?" to randomly selected samples of community and hospital pharmacists from Alberta, Canada. ${ }^{11,12}$ In the community pharmacist sample, $45 \%$ of responses were considered product-focused (e.g., "fill prescriptions"), whereas only $29 \%$ were patient-centred (e.g., "address patients' medication needs"). ${ }^{11}$ Among hospital pharmacists, only $24 \%$ of responses to this question were patient-centred (e.g., "work as a member of the health care team to improve individual patient's health"), whereas over half of the responses were related directly to drugs (rather than patients, e.g., "calculating pharmacokinetics for certain medications") or were focused on drug distribution (e.g., "dispense prescriptions"). ${ }^{12}$ Taken together, the results of these studies suggest that pharmacy culture remains rooted in the traditional function of dispensing medications.

Although continued work to understand the professional culture of pharmacy is important, culture provides only part of the picture of pharmacy practice change. A better understanding of the personality traits of members of the profession is also needed, to provide a holistic picture of the way in which pharmacists respond to attempts to innovate practice. Theories of personality have shown that individuals' personalities comprise a number of traits, the blend of which characterizes human beings as individuals. ${ }^{13}$ In particular, 5 personality traits are widely recognized: extraversion, agreeableness, conscientiousness, neuroticism, and openness (Table 1). Together, these characteristics form the "Big Five" model of personality traits. ${ }^{13}$

A review of the personality literature reveals that these Big Five traits, alone or in combination, often influence work performance. ${ }^{14-18}$ For example, a recent study examining the relationship between work role performance and the Big Five traits revealed that openness was positively related to individual proactivity, ${ }^{17}$ whereby an individual finds a better way of accomplishing some work-related objective. Openness was also positively related to organizational proactivity or the efforts a person makes to improve efficiencies for the company. ${ }^{19}$ However, openness was negatively related to team and organizational proficiency ${ }^{17}$ (speaking well of the company to those on the outside). Interestingly, agreeableness had an inverse relationship with individual proactivity ${ }^{17}$ (the likelihood of individuals to challenge current circumstances to change or improve a situation). Conscientiousness was positively related to individual task proficiency (the ability to complete a task correctly), ${ }^{19}$ while the inverse was true for neuroticism and extraversion. ${ }^{17}$

\section{Table 1. Personality Dimensions of the Big Five Inventory ${ }^{13}$}

\begin{tabular}{ll}
$\begin{array}{l}\text { Dimension } \\
\text { Extraversion }\end{array}$ & $\begin{array}{l}\text { Description } \\
\text { as sociability, assertiveness, confidence, and ambitiousness. }\end{array}$ \\
\hline Agreeableness & $\begin{array}{l}\text { Describes the person's level of altruism, cooperation, willingness to } \\
\text { conform to group norms, and warmth or kindness. }\end{array}$ \\
\hline Conscientiousness & $\begin{array}{l}\text { Describes the ability to control impulses to facilitate goal-directed } \\
\text { behaviour. Those high in this trait follow norms and rules, and are } \\
\text { efficient in planning, organizing, and prioritizing tasks. }\end{array}$ \\
\hline Neuroticism & $\begin{array}{l}\text { Contrasts emotional stability with feelings of anxiety, nervousness, and } \\
\text { depression. Those high in this trait are self-conscious, moody, impulsive, } \\
\text { and prone to stress. }\end{array}$ \\
\hline Openness & $\begin{array}{l}\text { Describes the breadth and depth of one's life, including the originality } \\
\text { and complexity of experiences. Individuals high in openness are } \\
\text { knowledgeable, perceptive, and analytical; they seek out experiences } \\
\text { and are more artistic and investigative. }\end{array}$ \\
\hline
\end{tabular}


A narrative review found that extraversion was positively related to Holland's social (helping) and enterprising (persuading) job interests, that agreeableness was positively related to social (helping) job interests, and that openness was related to artistic (creative) and investigative (thinking) job interests. ${ }^{18}$ Conscientiousness was also shown to relate to having "conventional" interests. ${ }^{18}$ Finally, in a meta-analysis, Barrick and others $^{20}$ found that conscientiousness was a valid predictor of job performance across all job types tested and that neuroticism was inversely related to at least some job success predictors. To the best of our knowledge, however, there has been no research into the personality traits of pharmacists, especially as such traits relate to practice change. This study was undertaken to characterize the personality traits of hospital pharmacists practising in Alberta, Canada.

\section{METHODS}

A cross-sectional survey of hospital pharmacists was undertaken in Alberta, Canada. Invitations to participate in an anonymous web-based questionnaire were sent via e-mail to all 766 hospital pharmacists practising in urban and rural centres within the 2 health service organizations that provide all institutional care in the province. The survey invitations were distributed by the health care organizations, which ensured that no personal identifying information was available to members of the research team.

For this study, the Big Five Inventory was used to measure personality traits. This inventory is a validated, reliable instrument that measures extraversion, agreeableness, conscientiousness, neuroticism, and openness to new experiences (Table 1). ${ }^{13}$ It is considered a short instrument, using 44 phrases (hereafter referred to as "items") to describe personality traits. ${ }^{13}$ Each respondent ranks the 44 items on a Likert scale from 1 (strongly disagree) to 5 (strongly agree). The authors of the Big Five Inventory also developed a scoring scheme, which assigns a distinct subgroup of the 44 items, between 8 and 10 items, to each of the 5 personality traits. ${ }^{21}$

The primary purpose of this study, to characterize the personality traits of hospital pharmacists, was not revealed to potential participants. Rather, the study was described as intending "to better understand pharmacist learning styles and traits to enable us to support staff in the adoption of patientcentred care as articulated in the Blueprint for Pharmacy". This slight ambiguity was used to minimize any social desirability bias. The study received approvals from the Health Research Ethics Board of the University of Alberta and the operational leadership of the health care organizations.

Pharmacists' responses to the questionnaire were first scored according to the scheme provided by the authors of the Big Five Inventory, which treats the data at an interval level of measurement. ${ }^{21} \mathrm{~A}$ second analysis was then undertaken to account for the controversy surrounding the treatment of ordinally measured data as if it were interval data. ${ }^{22-24}$ In this second analysis, frequency counts of the responses to each item composing the Big Five personality traits were performed following the approach advocated by Clason and Dormody. ${ }^{22}$ For the purposes of this count, both ends of the Likert scale were truncated, to combine the "agree" and "disagree" options (i.e., responses of 1 and 2 [strongly disagree and disagree] were combined, as were responses of 4 and 5 [agree and strongly agree]). These combined options will be referred to as "agree" and "disagree". These item counts were then collated by personality trait to develop a visual scale of the total frequency of item responses. This presents an alternative view of the data that is more consistent with the level of measurement of Likert scales and provides a higher level of interpretability of the personality traits as they relate to pharmacy practice.

Measures of central tendency were calculated for each personality trait. Additional analyses, using univariate analysis of variance, were performed to assess any differences in responses related to age, duration of practice, role (front line versus management), full-time equivalence, location of hospital (urban versus rural), and whether or not pharmacists had additional prescribing authorization ${ }^{10}$ (received or planned for sometime within the next 6 months). The a priori level of significance for all statistical tests was 0.05 . Data were analyzed using SPSS software (version 19; SPSS Inc, Chicago, Illinois).

\section{RESULTS}

Of the 766 pharmacists invited to participate, 347 (45\%) completed the questionnaire. Of these, 297 (86\%) were staff pharmacists, $24(7 \%)$ were clinical practice leaders, and 22 (6\%) were managers. Eighty-two percent of respondents (267 of 326) were from urban practice centres, and 63\% (218 of 347) worked full-time. The average age of respondents was 41 years (standard deviation [SD] 11 years), and the average period in practice was 17 years (SD 11 years) (Table 2). Respondents' mean scores were 3.2 (SD 0.7) on extraversion, 3.8 (SD 0.4) on agreeableness, 4.0 (SD 0.4) on conscientiousness, 2.5 (SD 0.7) on neuroticism, and 3.5 (SD 0.6) on openness.

Univariate analysis of variance demonstrated a number of subgroup differences. Managers and staff pharmacists $\left(\mathrm{F}_{2,340}=4.63, p=0.010\right)$ and full-time and part-time pharmacists $\left(\mathrm{F}_{1,343}=7.23, p=0.008\right)$ differed on the extraversion trait. Specifically, managers were more extraverted than staff pharmacists and full-time staff more extraverted than part-time staff, with mean differences between the pairs of 0.45 $(p=0.014)$ and $0.22(p=0.008)$, respectively.

There was also a difference between staff pharmacists and clinical practice leaders on the trait of conscientiousness $\left(\mathrm{F}_{2,309}=4.35, p<0.05\right)$. The mean difference between the groups was $0.23(p<0.05)$, with clinical practice leaders 
Table 2. Baseline Characteristics of Participating Hospital Pharmacists $(n=347)$

\begin{tabular}{lrr} 
Characteristic & $\begin{array}{c}\text { No. (\%) of } \\
\text { Respondents* }\end{array}$ \\
\hline Age (years), mean \pm SD & $41 \pm 11$ \\
\hline Time in practice (years), mean \pm SD & $17 \pm 11$ \\
\hline Proportion of time spent in clinical practice & 83 & $(24)$ \\
$\leq 25 \%$ & 105 & $(30)$ \\
$26 \%-50 \%$ & 103 & $(30)$ \\
$51 \%-75 \%$ & 56 & $(16)$ \\
$\geq 76 \%$ & 48 & $(14)$ \\
\hline Additional prescribing authorization & 299 & $(86)$ \\
Has already obtained & & \\
Has not obtained & 43 & $(12)$ \\
\hline Plans to obtain additional prescribing & 168 & $(48)$ \\
authorization in next 6 months & 136 & $(39)$ \\
Yes & & \\
No &
\end{tabular}

$\mathrm{SD}=$ standard deviation.

*Except where indicated otherwise.

scoring slightly higher than staff pharmacists. Finally, there was a difference between urban and rural pharmacists on the trait of agreeableness $\left(\mathrm{F}_{1,326}=4.48, p<0.05\right)$. The mean difference was $0.12(p<0.05)$, with rurally based pharmacists scoring slightly higher than their urban counterparts. Subgroup analysis showed no difference between pharmacists who self-identified as having obtained additional prescribing authorization and those who had not done so.

Figure 1 shows the proportional representation of item responses for each of the personality traits. For the trait of extraversion, roughly $50 \%$ of the item responses fell into the "agree" category, with the remaining 50\% split between the "neutral" and "disagree" categories. For agreeableness, nearly $80 \%$ of the item responses were in the "agree" category, while only $13 \%$ fell into the "neutral" category and $7 \%$ in the "disagree" category. For the conscientiousness trait, $71 \%$ of item responses were clustered in the "agree" category, with $22 \%$ and $7 \%$ in the "neutral" and "disagree" categories, respectively. For the neuroticism trait, more than half $(52 \%)$ of the item responses fell into the "disagree" category, while the remaining $48 \%$ was spilt between the "neutral" and "agree" categories. For the openness trait, $53 \%$ of the item responses fell into the "agree" category, while $27 \%$ and $19 \%$ of the item responses fell into the "neutral" and "disagree" categories.

\section{DISCUSSION}

This study represents the first consideration of the personality traits of hospital pharmacists. We found that hospital pharmacists tended toward stronger expressions of the traits of extraversion, agreeableness, conscientiousness, and openness and were emotionally stable. Understanding the personality traits of hospital pharmacists may help to understand how practice can be shifted toward patient-centred care. It may also help in the development of training and support programs tailored specifically to the traits of hospital pharmacists or perhaps even to an individual's personality traits.

The trait with the greatest difference in item response frequencies between "agree" and "disagree", agreeableness, is characterized by helpful, unselfish, trusting, and compassionate behaviours. ${ }^{13}$ In many respects these characteristics are operationalized in the satisfaction ratings obtained in public opinion polls and surveys, wherein pharmacists are described by patients as being caring and compassionate health care providers. ${ }^{25}$ People who more strongly identify with this trait are also less apt to start quarrels or be rude to others. ${ }^{13}$ With respect to work behaviours, people who tend to exhibit this trait are more collectively or socially oriented in their

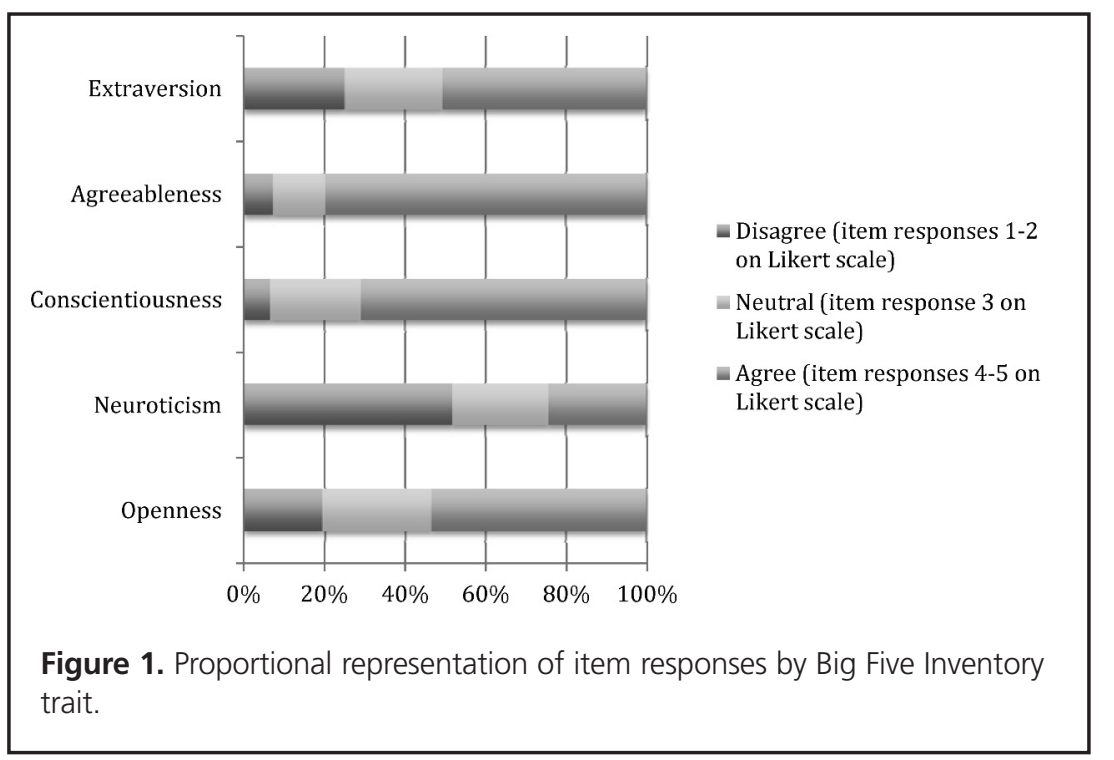


interests. ${ }^{17,18}$ An exemplification of these aspects of agreeableness may be observed in the pharmacy literature's traditional surrogate measure, physicians' acceptance of pharmacists' recommendations. ${ }^{26-29}$ This focus on physicians' acceptance of pharmacists' recommendations, to indicate the value of pharmacists' contributions, could also have been obtained with a chart review looking at changes in medication therapy. However, measurement of physicians' acceptance may simply demonstrate the importance to pharmacists of gaining approval from other members of the medical team, as opposed to indicating improvement in patient outcomes.

The trait of conscientiousness, which also had a substantial difference in response frequencies, is characterized by reliability, thoroughness, tenacity, efficiency, and organized behaviours. ${ }^{13}$ Furthermore, people who identify more with the items composing this trait are focused and careful ${ }^{13}$ and consequently less likely to make errors in job performance. ${ }^{17,19}$ These are important characteristics for traditional dispensing roles in the pharmacy, where such focused and careful attention is key to preventing medication errors. ${ }^{30,31}$ This drive to perfection in job performance may also be intuited from the proliferation of pharmacy research papers examining numbers of medication errors in various settings, so that they can be minimized. ${ }^{32-34}$

Openness, the third trait with a relatively strong difference in response frequencies, is characterized by originality, ingenuity, curiosity, and an artistic orientation. ${ }^{13}$ Within work settings, people who exhibit this trait also tend to be drawn to artistic or investigative types of work. ${ }^{18}$ The manifestation of this trait may be witnessed in the proliferation of literature from a subpopulation of the pharmacy profession, typically in academic and advanced practice settings, admonishing pharmacists to abandon their "traditional" roles and adopt new practices. ${ }^{1,35,36}$ However, manifestation of this trait may be complicated by the characteristics expressed by the conscientiousness trait, focusing on mastery of tasks, which may not be compatible with the uncertainty and "greyness" that come with the new practice approaches being touted. Indeed, Farrell and others,$^{37}$ examining the integration of pharmacists into family medicine teams, found a distinct difference in comfort levels between pharmacists and physicians when approaching direct patient care.

The remaining 2 traits showed less difference between "agree" and "disagree" for trait items. One of these traits, extraversion, is characterized by talkativeness, energy, and an outgoing disposition. ${ }^{13}$ People who identify more strongly with this trait have an assertive personality and are neither shy nor inhibited $^{13}$; they have also been found to have a higher degree of social (helping) and enterprising (persuading) job interests ${ }^{17}$ but lower proficiency in work-related tasks that they must complete on their own. ${ }^{18}$ A possible explanation for the greater similarity between the "agree" and "disagree" categories for this trait may be found in an examination of subgroup differences (Figure 2). It appears that pharmacists who had already obtained their prescribing authorization were slightly more likely to agree with items related to this trait, which suggests that something distinguishes them from their nonprescribing colleagues. Further research into this difference is required before any stronger conclusions can be drawn.

The other trait with less difference in response frequencies was neuroticism, a trait characterized by behaviours that include feeling "blue" or depressed, tense, moody, and nervous. ${ }^{13}$ People who more strongly identify with this trait are less able to handle stress and worry more than other people. ${ }^{13}$

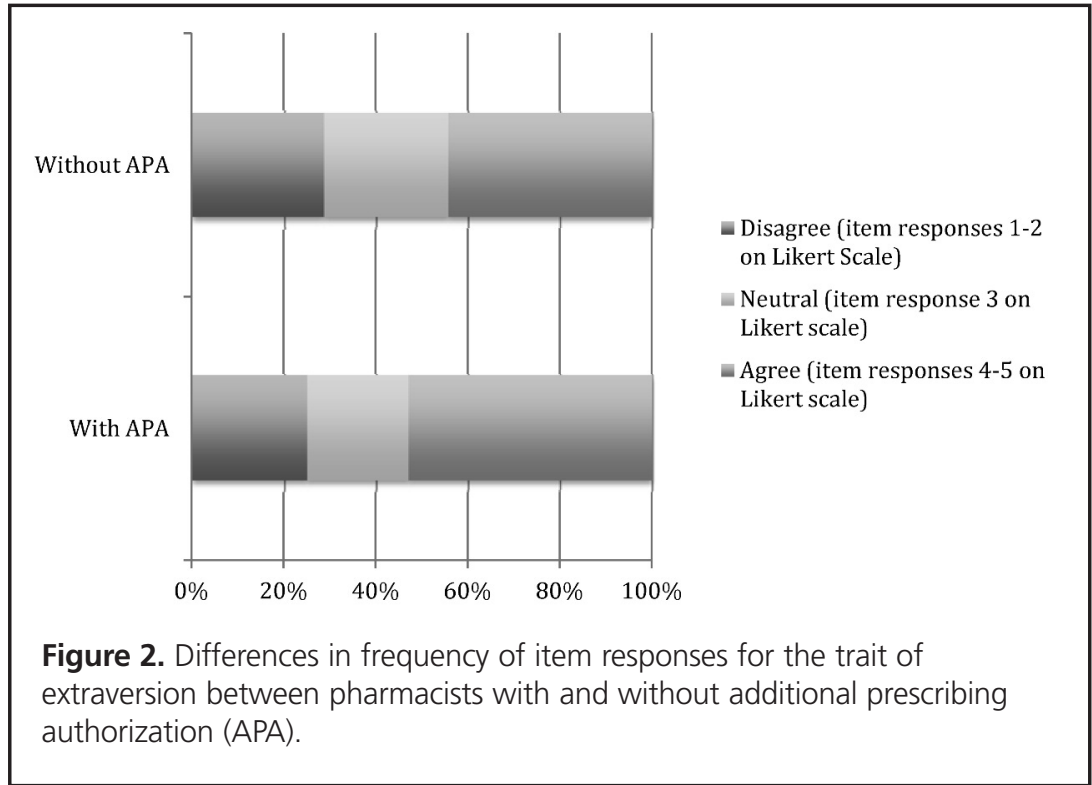


In terms of work, people who more strongly identify with this trait tend to have a lower ability to complete work tasks properly ${ }^{17}$ and tended to be less successful on some job success measures. ${ }^{20}$ However, most of the respondents in the current study did not agree with the items for this trait, which suggests that they did not feel tense or stressed, but instead felt quite emotionally stable.

Our study into the personalities of hospital pharmacists offers an alternative approach to exploring the reasons why change within the profession has been spotty and incomplete. The interpretation of the results provides some insight into pharmacists' (and pharmacy researchers') persistence in seeking approval from other health care professionals and their possible trepidation in adopting practices wherein perfection is more difficult to attain or define. We propose that future research into the personality traits of pharmacists focus more specifically on the potential malleability of trait manifestations. This could be achieved by coupling the Big Five Inventory with instruments such as the Expanded Skills Confidence Inventory, an instrument based on the self-efficacy themes that are thought to be amenable to intervention. ${ }^{38,39}$

Another possible research approach comes from work conducted by Hackman and Oldham, ${ }^{40}$ who studied the design of work. These authors advocated change in the structure of work itself, rather than an expectation that employees will adapt to the work in its existing form. ${ }^{40}$ That is, rather than merely telling pharmacists that they need to adopt new practice opportunities out of professional obligation, leaders in the profession might be able to achieve greater change by completely disrupting traditional work routines (e.g., by removing all dispensing responsibilities) and putting into place supports to integrate new models of practice. However, such an approach also demands that the wider pharmacy profession accept that many pharmacists would not be able to make the necessary changes to allow expansion of roles without significant support.

This study had several limitations which merit consideration. First, no measures were used to determine the effect of intentional "faking" on the survey, although steps were taken to minimize socially desirable responses through the promise of anonymity of data and a slight misrepresentation of the study's purpose. Second, the results describe the personality traits of only the hospital pharmacists who responded; it is not known if these respondents are representative of all hospital pharmacists. Finally, the Big Five Inventory is not intended as an explanatory tool. However, it does allow for the generation of hypotheses about how various personality traits may manifest in a particular working environment.

To the authors' knowledge, this is the first study of personality traits among hospital pharmacists. The research team believes that the Big Five Inventory, coupled with knowledge gained about the culture of pharmacy, will be useful for improving the understanding of work-related behaviours of pharmacists. Such understanding will allow conceptualization of how new practice opportunities may best be realized, which will benefit the profession and, most importantly, patient care.

\section{References}

1. Task Force on a Blueprint for Pharmacy. Blueprint for pharmacy: the vision for pharmacy. Ottawa (ON): Canadian Pharmacists Association; 2008 [cited 2011 Oct 13]. Available from: http://blueprintforpharmacy.ca/docs/ pdfs/2011/05/11/BlueprintVision.pdf?Status=Master

2. CSHP 2015 - targeting excellence in pharmacy practice. Ottawa (ON): Canadian Society of Hospital Pharmacists; 2013 [cited 2013 Jan 8]. Available from: www.cshp.ca/programs/cshp2015/

3. Pharmacy practice model initiative. Bethesda (MD): American Society of Health-System Pharmacists; 2013 [cited 2013 Jan 8]. Available from: www.ashpmedia.org/ppmi/

4. Doering PL. Prescribing authority for pharmacists, Florida style: a home run or a swing and a miss? Ann Pharmacother. 2007;41(11):1878-83.

5. Kröger E, Moisan J, Grégoire JP. Billing for cognitive services: understanding Québec pharmacists' behavior. Ann Pharmacother. 2000;34(3):309-16.

6. Chan P, Grindrod KA, Bougher D, Pasutto FM, Wilgosh C, Eberhart G, et al. A systematic review of remuneration systems for clinical pharmacy care services. Can Pharm J. 2008;141(2):102-12.

7. Jorgenson D, Lamb D, MacKinnon NJ. Practice change challenges and priorities: a national survey of practising pharmacists. Can Pharm J. 2011;144(3):125-31.

8. Grindrod KA, Lynd LD, Joshi P, Rosenthal M, Isakovic A, Marro CA. Pharmacy owner and manager perceptions of pharmacy adaptation services in British Columbia. Can Pharm J. 2011;144(5): 231-5.

9. Marra C, Lynd L, Grindrod K, Joshi P, Isakovic A. An overview of pharmacy adaptation services in British Columbia [abstract]. Proceedings of the Canadian Pharmacists Association Conference; 2010 May 17; Calgary (AB).

10. Yuksel N, Eberhart G, Bungard TJ. Prescribing by pharmacists in Alberta. $A m$ J Health Syst Pharm. 2008;65(22):2126-32.

11. Rosenthal MM, Breault RR, Austin Z, Tsuyuki RT. Pharmacists' selfperception of their professional role: insights into community pharmacy culture. J Am Pharm Assoc. 2011;51(3):363-7.

12. Al Hamarneh YN, Rosenthal M, McElnay JC, Tsuyuki RT. Pharmacists' perceptions of their professional role: insights into hospital pharmacy culture. Can J Hosp Pharm. 2011;64(1):31-5.

13. John OP, Naumann LP, Soto CJ. Paradigm shift to the integrative big-five trait taxonomy: history, measurement, and conceptual issues. In: John OP, Robins RW, Pervin LA, editors. Handbook of personality: theory and research. New York (NY): Guilford Press; 2008. p. 114-58.

14. Barrick MR, Mount MK. The big five personality dimensions and job performance: a meta-analysis. Pers Psychol. 1991;44(1):1-26.

15. Bono JE, Judge TA. Personality and transformational and transactional leadership: a meta-analysis. J Appl Psychol. 2004;89(5):901-10.

16. Thoresen CJ, Bradley JC, Bliese PD, Thoresen JD. The big five personality traits and individual job performance growth trajectories in maintenance and transitional job stages. J Appl Pyschol. 2004;89(5):835-53.

17. Neal A, Yeo G, Koy A, Xiao T. Predicting the form and direction of work role performance from the Big 5 model of personality traits. J Organ Behav. 2012;33(2):175-92.

18. Ozer DJ, Benet-Martínez V. Personality and the prediction of consequential outcomes. Annu Rev Psychol. 2006;57:401-21.

19. Griffin MA, Neal A, Parker SK. A new model of work role performance: positive behavior in uncertain and interdependent contexts. Acad Manag J. 2007;50(2):327-47.

20. Barrick MR, Mount MK, Judge TA. Personality and performance at the beginning of the new millennium: What do we know and where do we go next? Int J Sel Assess. 2001;9:9-30.

21. The big five inventory: frequently asked questions. Berkeley (CA): Berkeley Personality Lab; 2007-2009 [cited 2011 Oct 13]. Available from: www.ocf.berkeley.edu/-johnlab/bfi.htm 
22. Clason DL, Dormody TJ. Analyzing data measured by individual Likert-type items. J Agric Educ. 1994;35(4):31-5.

23. Jamieson S. Likert scales: how to (ab)use them. Med Educ. 2004; 38(12):1217-18.

24. Norman G. Likert scales, levels of measurement and the "laws" of statistics. Adv Health Sci Educ Theory Pract. 2010;15(5):625-32.

25. What do pharmacists, doctors, soldiers, pilots and teachers have in common? They're among the most trusted professions in Canada. Toronto (ON): Ipsos Reid; 2011 [cited 2013 May 8]. Available from: http://blueprintforpharmacy. ca/docs/pdfs/proftrust-report---ipsos-reid---jan-4-2011.pdf

26. McCollum M, Nuffer W, Ellis SL, Turner CJ. Physician acceptance of pharmacotherapy recommendations made by pharmacy students in a rural pharmacy-based diabetes care and education clinic. Am J Pharm Educ. 2009;73(2):24.

27. Rhoads M, Thai A. Physician acceptance rate of pharmacist recommendations to reduce use of potentially inappropriate medications in the assisted living setting. Consult Pharm. 2003;18(3):241-7.

28. Anderegg SV, Demik DE, Carter BL, Dawson JD, Farris K, Shelsky C, et al. Acceptance of recommendations by inpatient pharmacy case managers: unintended consequences of hospitalist and specialist care. Pharmacotherapy. 2013;33(1):11-21.

29. Root R, Phelps P, Brummel A, Else C. Implementing a pharmacist-led medication management pilot to improve care transitions. Innov Pharm. 2012;3(2):Article 75.

30. Grasha AF. Psychosocial factors, workload and risk of medication errors. US Pharm. 2003 Jan 23 [cited 2013 Jan 8];27(4). Available from: http:// pharmsafety.org/extras/PsychosocErr.pdf

31. Grasha AF. Pharmacy workload: the causes and confusion behind dispensing errors. Can Pharm J. 2001;134(3):26-35.

32. Hellström LM, Bondesson A, Höglund P, Eriksson T. Errors in medication history at hospital admission: prevalence and predicting factors. BMC Clin Pharmacol. 2012;12:9.

33. Murray MD, Ritchey ME, Wu J, Tu W. Effect of a pharmacist on adverse drug events and medication errors in outpatients with cardiovascular disease. Arch Intern Med. 2009;169(8):757-63.

34. Brown JN, Barnes CL, Beasley B, Cisneros R, Pound M, Herring C. Effect of pharmacists on medication errors in an emergency department. Am J Health Syst Pharm. 2008;65(4):330-3.

35. Rosenthal M, Austin Z, Tsuyuki RT. Are pharmacists the ultimate barrier to pharmacy practice change? Can Pharm J. 2010;143(1):37-42.

36. Tsuyuki RT, Schindel TJ. Changing pharmacy practice: the leadership challenge. Can Pharm J. 2008;141(3):174-80.

37. Farrell B, Ward N, Dore N, Russell G, Geneau R, Evans S. Working in interprofessional primary health care teams: What do pharmacists do? Res Social Adm Pharm. 2013;9(3):288-301.

38. Judge TA, Erez A, Bono JE, Thoresen CJ. Are measures of self-esteem, neuroticism, locus of control, and generalized self-efficacy indicators of a common core construct? J Pers Soc Psychol. 2002;83(3):693-710.
39. Hartman RO, Betz NE. The five-factor model and career self-efficacy: general and domain-specific relationships. J Career Assess. 2007;15(2):145-61.

40. Hackman JR, Oldham GR. Work redesign. Reading (MA): Addison-Wesley; 1980.

Jill Hall, BScPharm, ACPR, PharmD, was, at the time of this study, a PharmD student at the Leslie Dan Faculty of Pharmacy, University of Toronto, Toronto, Ontario. She is now a Clinical Assistant Professor in the Faculty of Pharmacy and Pharmaceutical Sciences, University of Alberta, Edmonton, Alberta.

Meagen Rosenthal, MA, is a PhD student at EPICORE Centre/ COMPRIS, Faculty of Medicine and Dentistry, University of Alberta, Edmonton, Alberta.

Hannah Family, MSc, MBPsS, is a PhD student in the Department of Pharmacy and Pharmacology, University of Bath, Bath, England.

Jane Sutton, PhD, CPsychol, AFBPsS, is a Lecturer in the Department of Pharmacy and Pharmacology, University of Bath, Bath, England.

Kevin Hall, BSc(Pharm), PharmD, is a Clinical Associate Professor, Faculty of Pharmacy and Pharmaceutical Services, University of Alberta, Edmonton, Alberta.

Ross T Tsuyuki, BSC(Pharm), PharmD, MSC, FCSHP, FACC, is Professor of Medicine (Cardiology) and Director, EPICORE Centre/COMPRIS, Faculty of Medicine and Dentistry, University of Alberta, Edmonton, Alberta.

Competing interests: Ross Tsuyuki serves on the BMS-AstraZeneca Advisory Board for Access with Evidence Development programs; serves as a consultant and Pharmacy Advisory Board member for PharmaSmart International; serves as a consultant for Merck; serves on the advisory board for the MAVIKontrol patient support program sponsored by Abbott; has received institutional grants from Sanofi and AstraZeneca for investigator-initiated trials; and serves as a member of the Boehringer Ingelheim data monitoring board for dabigatran studies. Kevin Hall is one of the managing editors for the Hospital Pharmacy in Canada Report and receives payment for managing survey design, data analysis, and editing of the written report. None declared for Jill Hall, Meagan Rosenthal, Hannah Family, and Jane Sutton.

\section{Address correspondence to:}

Dr Ross Tsuyuki

EPICORE Centre

Department of Medicine

3rd Floor, Brain and Aging Research Building (BARB)

University of Alberta

Edmonton AB T6G 2M8

e-mail: ross.tsuyuki@ualberta.ca 